\title{
Remotely Accessible Solar Energy Laboratory For High School Students
}

\author{
William Hutzel ${ }^{1}$ and David Goodman ${ }^{2}$
}

\begin{abstract}
A remotely accessible solar energy laboratory has been developed for real-time experimentation using solar heating and photovoltaic equipment that is physically located at Purdue University. Indiana high school students are the first customers for this on-line resource. In addition to sensor data, the web-based laboratory includes lesson plans, tutorials, assessment questions, and a feedback utility. This project is helping science teachers meet new state science standards from the Indiana Department of Education, which call for hands-on laboratory activities and real time data analysis. Remotely accessed labs are becoming popular because they offer the opportunity for large numbers of students to learn from state-of-the-art equipment. The cost of expensive laboratory equipment is easier to justify if it can be widely used.
\end{abstract}

Index Terms - remote access, solar energy, $K-12$ outreach

\section{TARGETING SOLAR ENERGY}

What happens when the demand for energy exceeds the supply? This is a very real (and scary) prospect for the United States. The U.S. Energy Information Administration predicts that in just two decades we will need 175 quads (1 quad $=10^{15}$ Btu's) to meet anticipated energy demands. That is $75 \%$ more energy than is used today. Solar energy is one of several promising technologies with the potential to reduce the demand for diminishing fossil fuels. Despite being abundant, renewable, and non-polluting, solar energy is not widely understood or deployed. It is surprising that solar energy contributes less than $0.1 \%$ of the energy annually used in the U.S.

To help improve awareness of alternative energy the Mechanical Engineering Technology (MET) Department at Purdue University in West Lafay ette is featuring solar energy as part of its routine lab-based coursework. Figure 1 illustrates a $3 \mathrm{~kW}$ photovoltaic array and a $9 \mathrm{~kW}$ solar heating system that have been constructed on the roof of the Knoy Hall of Technology. One experiment in an undergraduate thermodynamics course computes the efficiency of the solar heating system [1]. Another related experiment has students determine the overall efficiency of the photovoltaic power system [2]. These solar energy experiments achieve two course goals. Firstly, they demonstrate the sensible energy and power computations that are important in any introductory thermodynamics course. As an extra bonus, they also introduce students to one possible source of renewable energy.

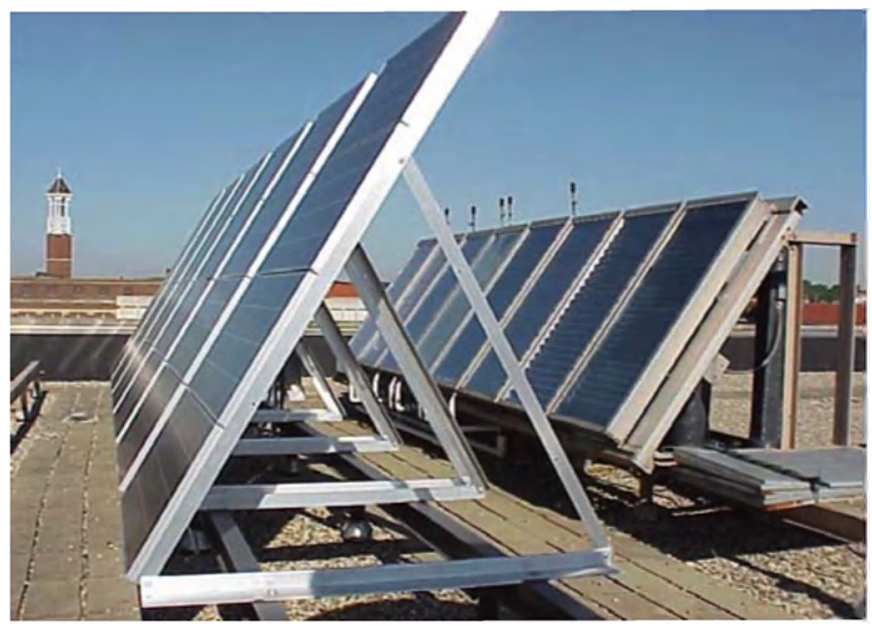

FIGURE 1

SOLAR ENERGY EQUIPMENT AT PURDUE UNIVEERSITY DEMONSTRATES ENERGY CONVERSION PROCESSES.

Figure 1 also illustrates one of the drawbacks to solar energy education. The laboratoiy equipment tends to be large, cumbersome, and located in inaccessible places such as the rooftop shown here. These one-of-a-kind installations are fine for demonstrations but are not easily adapted for handson use by lab-sized groups of 15-20 students because there is simply not enough physical equipment. It is difficult to capture a student's attention while sharing one temperature sensor or multimeter among a large group. To address the over-crowding issue, the MET Department added a networkbased controller to the existing solar energy equipment. Rather than making measurements in person, students accessed sensor data over the Internet [3].

Figure 2 shows the building automation system from KMC Controls that has provided Internet access for approximately 5 years. It is a commercially available controller that is more typically used for managing the mechanical systems in modem commercial buildings. The panel has over 50 sensors for monitoring pressures, flows, temperatures, and electric power. The panel also has about a dozen actuators for regulating pumps, fans, and valves. The only drawback to this system is that a proprietary pc-based

1 William Hutzel, Associate Professor, Mechanical Engineering Technology, Purdue University, West Lafayette, IN, wjhutzel@tech.purdue.edu 2 David Goodman, Graduate Student, School of Teecthmolloy, Purdue University, West Lafayette, IN, dwgoodman@tech.purdueedu 
software program, called WinControl ${ }^{\mathrm{TM}}$, is needed to unscramble the Internet signal. Until recently this software program limited Internet access to students working within the confines of the Knoy Hall of Technology.

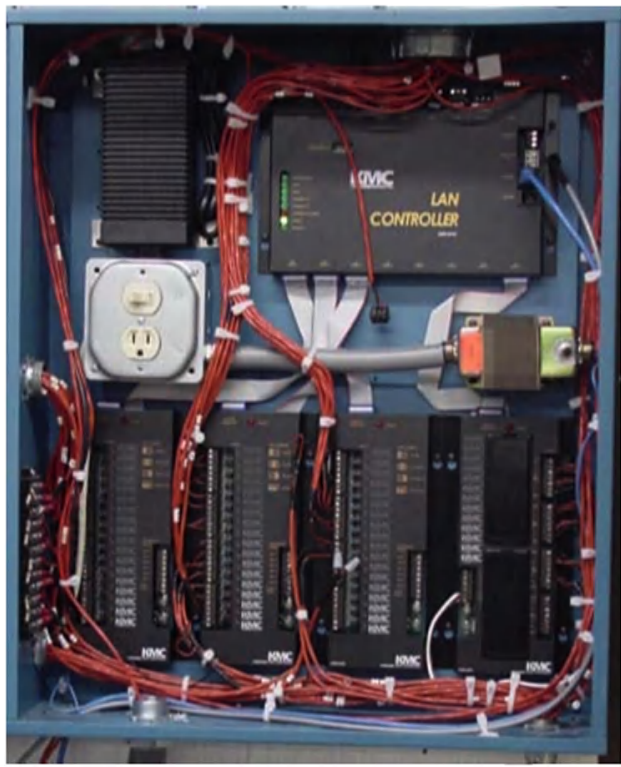

FIGURE 2

MOODERN BUILDING AUTOMIATION SYSTEMIS ARE WEB-ENAABLED

Like most modern business enterprises, the building control industry has been rapidly migrating toward network technologies that provide universal access to data via the Internet, cell phones, and web-enabled PDA's. Following these industry trends, a web portal was recently added to the existing solar energy system. A WebLite ${ }^{\mathrm{TM}}$ controller, also from KMC Controls, acquires real time performance data from thie original controller and posts it to the web in an html format. This open protocol allows any computer user with Internet access and a web browser to view live solar energy data. With the proprietary element of monitoring and control removed, the solar energy laborattony can begin serving a much larger audience.

The MET Department invested more than $\$ 20,000$ for building automation hardware to put the solar energy laboratory on the web. The dollar figure is onlyy for sensors, actuators, and networked controllers and does not include the actual solar equipment. This relatively high cost was justified based on the large population it serves. The remotely accessible laborattonyy equipment is

1. educating traditional residential college students

2. improving lab resources at Purdue satellite campuses

3. providing outreach opportunities for high schools

This paper focuses on topic 3. With generous support from the Indiana Higher Education Telecommunication System, KMC Controls, and Carrier Corporation, the MET Department is actively involved in a solar energy outreach initiative that involves Indiana high schools.

\section{REAMOTE ACCess FOR Higih SCHOOL OUTREACH}

This audience for a remotely accessible solar energy laboratory for high schools is enormous. Even though new state science standards from the Indiana Department of Education call for hands-on laboratory activities and realtime data analysis, many high schools lack the equipment to conduct real experiments. Our first visit to an Indiana high school demonstrated the extent of this problem. Modem personal computers and high speed internet access were readily available, but lab equipment for Physics was nonexistemit Instead of real experiments, a variety of computer simulations were used to demonstrate fundamental principles of mechanics, optics, and energy. The Physics teacher we encountered was very receptive to any resource that provided convenient access to real experimental data.

Using web-based remote access as a mechanism for K12 outreach is not entirely new. Iowa State University has been working for several years on a project that makes a scanning electron microscope available to science teachers over the web [4]. Researchers on that project learned that providing teachers remote access to sophisticated equipment does not guarantee that it will be used. Recruiting teachers and providing them with training was crucial to the success of that project.

Based on the findings at Iowa State, marketing the remote access solar enengy' laborattony' to high school science teachers became an important goal for the project. Several techniques were attempted. Direct contact with local science teachers by phone and email was successful, but labor intensive. Contacting teachers by a mass email through a state-supported science teacher listserve reached a larger audience, but the response rate was relatively low. Figure 3 shows that an exhibit at a statewide science teacher convention was used to showcase this new laboratory resource. In retrospect, all three techniques (direct contact, mass email, and exhibits) played a role in disseminating project informatiom.

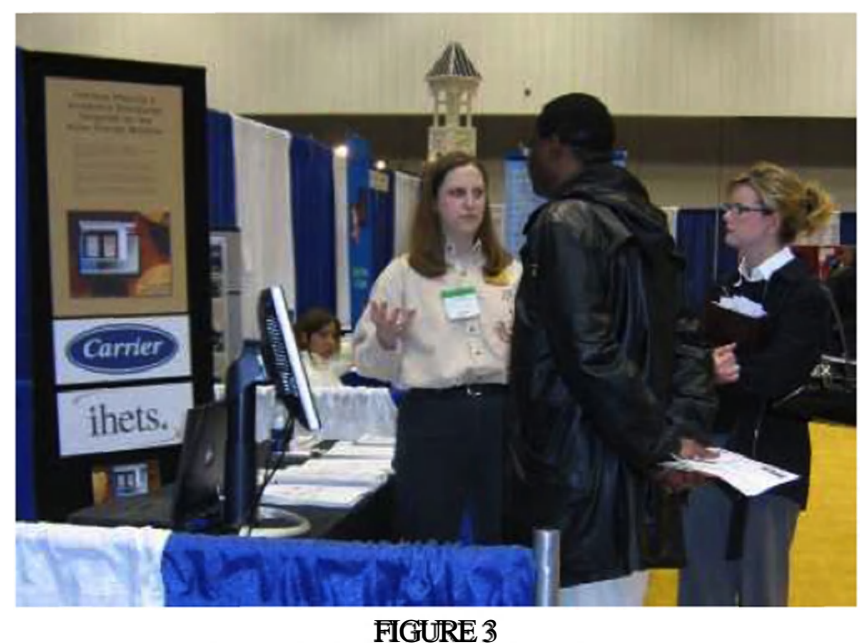

SCIENCE TEACHERS WERE RECRUITED AT A CONVENTION. 


\section{Session S2D}

\section{INSTRUCTIONAL DESIGN FOR K-12}

The four broad educational objectives that were targeted by this project are listed below. The objectives are not specific to solar energy, but represent concepts that should be considered for any laboratory investigation. These objectives are based on the results of an ABET-sponsored colloquium that broad identified learning objectives common to all laboratory based courses [5]. These objectives provided a broad framework for the instructional design by illuminating key components of laboratory work. Preface each of the following statements with the phrase "Laboratory investigations will teach students to:"

1. Identify the strengths and limitations of theoretical models as predictors of real behavior.

2. Collect, analyze, and interpret data and to form and support conclusions.

3. Recognize unsuccessful experimental outcomes.

4. Recognize the scale and sophistication of mechanical and electrical systems.

As an example, objective 2 recognizes that experiments should teach students to collect, analyze, and interpret data. This objective was helpful in determining how a remote lab should represent numeric information. Since a real experiment involves physically recording data in different parts of a system, the graphic interface in Figure 4 was designed to display the performance of two different solar heating panels that use air as the energy transport medium. Each temperature and flow data point for the collectors was presented in the location that corresponds to the physical position of the real sensor. The organization of the graphic interface is a minor point, but it would have been much simpler to summarize data in a tabular format.

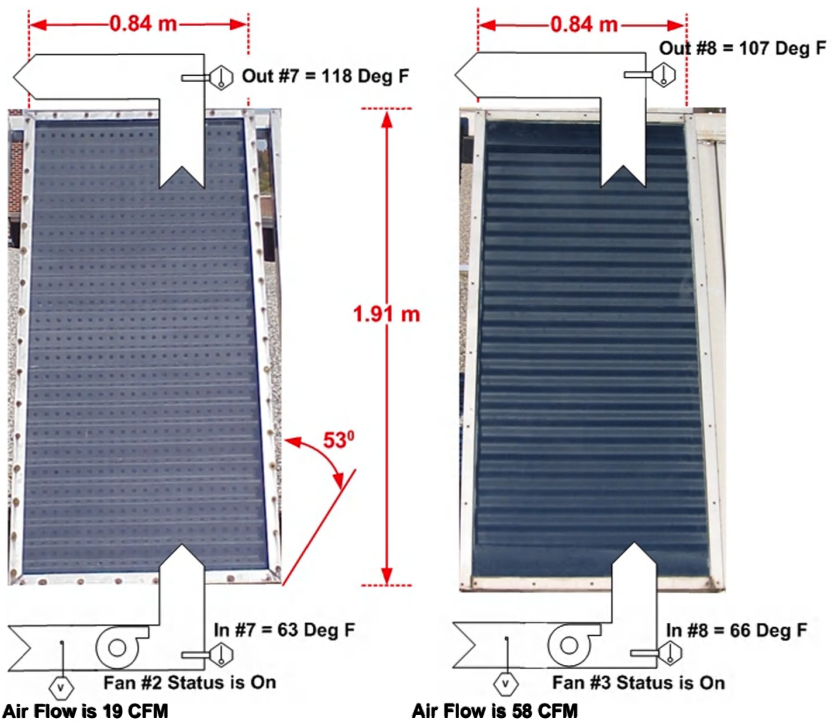

FIGURE 4

COMPARATINE SEMSOR DatTa IS SHOWM ATT ITS PHYY STCAL LOCAUTON.
The remotely accessible solar energy laboratory was designed to help high school science teachers meet new state academic standards from the Indiana Department of Education. In addition to encouraging hands-on laboratory activities and real time data analysis, the standards include a comprehensive list of technical topics that must be taught as part of the core high school science curriculum. Three science academic standards that were targeted are listed below. All three standards are part of the requirements for an introductory "Physics I" course that includes a broad segment on the nature of energy.

1. Use the law of conservation of energy to predict the outcome of an energy transformation.

2. Use the concepts of temperature, thermal energy, transfer of thermal energy, and the mechanical equivalent of heat to predict the results of an energy transfer.

3. Explain the relation between energy and power. Explain the definition of the unit of power, the watt.

The remote access solar energy laboratory addresses the high school academic standards listed above by having students evaluate the energy conversion efficiency of solar heating and photovoltaic systems. "Energy conversion efficiency" is defined as the ratio of useful energy collected to the broadband radiant energy available from the sun. This experimental work is a simplified version of an analysis that is routinely carried out by MET students in an introductory thermodynamic course at Purdue University. The high school experiment is an adobe file that can be downloaded from the remote access website identified later in this paper. References [1] and [2] provide a detailed explanation and example calculations for these efficiency investigations.

Five specific learning outcomes for the high school version of the remotely accessible solar energy experiment are listed. After completing the lab experiment, outcome 1 shows that students will be able to use on-line measurements of temperature and flow for computing the thermal power collected by an active loop heating panel. Outcome 2 has a similar goal, but uses the volts and amps produced by a photovoltaic array to determine electric power. Outcome 3 uses measurements from a solar pyranometer as the basis for efficiency calculations. Outcome 4 forces students to look back on the efficiency computations and recognize that not all of the sun's energy was converted into useful energy. Outcome 5 has students view the current weather forecast and make projections about how ambient conditions influence solar collector performance. Preface each of the following statements with the phrase "After completing the remotely accessible solar energy lab, a student will be able to:"

1. Explain the relationship between temperature, flow, and thermal power for an active loop solar heating panel.

2. Explain the relationship between current, voltage, and electrical power for a photovoltaic panel.

October 20 - 23, 2004, Savannah, GA

\section{0-7803-8552-7/04/\$20.00 @ 2004 IEEE}


3. Quantify radiant power from the sun based on pyranometer measurements.

4. Recognize that energy conversion processes are less than $100 \%$ efficient.

5. Interpret weather trends to help explain the performance of solar energy equipment.

\section{COMPREHENSIVE WEBSITE}

Go to http://www.tech.purdue.edu/met/facilities/knoy427/ remote/hs/index.html to view the remote access solar energy website that has been created for high school science teachers. The web site has six main menu headings: Home, Instruction, Live Data, Tutorial, Weather, Contact Info, Feedback, and Solar Links. Most of the headings are self explanatory. The menu bar appears as a handy reference from anywhere within the remote access site.

The Home menu has links to the remote access solar home page, the MET Departmental home page, and the Purdue University home page.

The Instruction menu contains most of the classroom aids for teachers. It includes an overview presentation about solar energy, a downloadable version of the solar energy experiment, information about the Indiana high school science academic standards being targeted, and an overview of the computer requirements (access speed, screen resolution, etc.) for using the remote access site. A downloadable version of assessment questions for students is particularly important. The principal investigators for this project are keenly interested in working with high school science teachers to evaluate student performance in this remote access setting.

The user must link to a separate web-based environment to complete the remote experiment. The Live Data menu is a direct link to web-based solar energy data from the Weblite ${ }^{\mathrm{TM}}$ controller. Since the procedure for navigating around the Weblite $^{\mathrm{TM}}$ controller is not overly obvious to a first-time user, the Tutorial menu has simple screen animations that demonstrate basic mouse actions and key strokes. Separate tutorials show how to $\log$ on to the controller, view instantaneous solar energy data, and access long term performance trends.

The Weather menu accesses a website with weather forecasts for West Lafayette, IN. Since this is a remotely accessible laboratory the ambient conditions may be different from local weather conditions for the distance learners. It is important for students to visit the site and begin to recognize the correlation between weather conditions and solar energy performance.

The Contact Information menu is a listing of the support staff for the remotely accessible solar energy laboratory. This is a convenient way for high school teachers and students to contact support staff with questions on experimental work. It is our goal to check for email correspondence at least once each day.

Just as the name implies, the Feedback menu is an opportunity for students and teachers to provide email 0-7803-8552-7/04/\$20.00 @ 2004 IEEE comments on the solar energy laboratory. Direct feedback is the key mechanism for collecting comments to guide continuous improvement efforts.

The Solar Links menu bar is an index to a few of the many helpful websites with additional information about solar energy. As can be expected, the U.S. Department of Energy and Sandia National Laboratory have web sites with lots of practical solar information.

\section{EXPERIENCE WITH HIGH SCHOOLS}

Table I is an excerpt from a survey that was given to four teachers who attended a solar energy workshop at a large science teacher convention. The teachers participated in a presentation on solar energy and viewed the remote access website. Note that this survey data was collected before the teachers had attempted the remote access lab in front of their students. The teachers responded to each survey question on a scale of $1-5$, with a "1" indicating strong disagreement and a " 5 " indicating strong agreement to the corresponding statement. Even though relatively few teachers participated in this survey, it is preliminary evidence of teacher support for this remote access project.

TABLE I

SCIENCE TEACHERS SUPPORTED REMOTE ACCESS.

\begin{tabular}{|l|c|}
\hline SURVEY QUESTION NUMBER & $\begin{array}{c}\text { AVERAGE } \\
\text { TEACHER } \\
\text { RESPONSE }\end{array}$ \\
\hline $\begin{array}{c}\text { 2. The material presented by the Remotely } \\
\text { Accessible Solar Energy Lab is } \\
\text { appropriate for Physics students. }\end{array}$ & 4.0 out of 5.0 \\
\hline $\begin{array}{c}\text { 3. A Remotely Accessible Solar Energy } \\
\text { Lab is a good way to teach students } \\
\text { about solar energy and energy } \\
\text { conversion concepts. }\end{array}$ & 4.5 out of 5.0 \\
\hline $\begin{array}{c}\text { 6. I am interested in teaching this material } \\
\text { to my students. }\end{array}$ & 4.0 out of 5.0 \\
\hline
\end{tabular}

The engagement goal for this outreach project in terms of numbers of high school students was relatively modest. We had hoped to work with up to five high schools while evaluating the prototype version of the remotely accessed solar energy lab. Even though a large number of schools were contacted, we ended up partnering with only two high schools during the first semester that the lab was available. With up to three different classes of students (Physics I, Physics II, and Earth Science) at each school participating, approximately 100 students were engaged in the initial offering.

In March of 2004, teams of Purdue graduate students personally visited the two partner high schools to talk about solar energy and help students complete the solar laboratory experiment over the web. The personal visits were labor

October 20 - 23, 2004, Savannah, GA

\section{$34^{\text {th }}$ ASEE/IEEE Frontiers in Education Conference}


intensive, but necessary to begin collecting feedback on the overall success of the remote access project. This data is still being analyzed, but the preliminary responses are encouraging.

Students were asked to rate the quality of the remote solar laboratory exercise from 1 to 5 , with 5 being best. The median score for 34 student respondents was a "4" in terms of "ease of understanding" and "helpfulness". We were particularly pleased that the median score for the survey question that evaluated students overall interest in the solar energy topic was a "4" (out of 5). Final results from these prototype efforts will be presented at the October 2004 Frontiers in Education Conference.

The informal feedback we've received so far from science teachers are relatively minor. For example, one teacher has had a small amount of trouble with unit conversions. The remote access solar energy lab was developed with U.S. Customary units and this science teacher is more comfortable with SI units. We are still working to resolve this issue. On one hand, U.S. Customary units still dominate routine thermal energy computations in the United States. However, we understand that many science disciplines have already made the switch to metric units. Displaying dual units may be a reasonable compromise.

One other small indicator of success is the number of "hits" to the remotely accessible solar energy website. A simple counter logged several hundred hits to the remote accessed solar laboratory site in the first few weeks of full operation. A good number of the hits are from the web development team, but we are confident that a fair number of science teachers are monitoring this website. We expect the number of contact to grow as more teachers become aware of this lab resource.

After the prototype remote access solar energy lab is fully evaluated and changes recommended by high school science teachers and students are made, the long term implementation plan will avoid extensive traveling by Purdue faculty and staff. The goal is to begin bringing high school science teachers to the West Lafayette campus of Purdue for a free one-day workshop on applications of solar energy. While they are on campus, we plan to teach them about solar energy, show them the solar equipment, and demonstrate how to remotely access the lab's data over the Internet. After they return home, teachers and their students will access the solar energy web site to complete real-time experiments using the solar equipment that is physically located at Purdue. Recognizing that teachers will have questions, we plan to maintain a technical support team to provide fast and convenient troubleshooting assistance by phone or email.

\section{CONCLuSION}

A remotely accessed solar energy laboratory will be a useful outreach tool for Indiana high schools. It was a large undertaking the construct the laboratory facility, add the remote access feature, and complete the instructional design for high school students. On the other hand, it should be cost effective to operate and maintain, particularly because it is used by large numbers of undergraduate students and high school students. Preliminary indications are that we will be successful with our long term goal of helping increase the pool of technically literate high school students.

\section{ACKNOWLEDGMENT}

Developing and deploying this remotely accessible solar energy laboratory was a large undertaking. The project was made possible by generous support from the Indiana Higher Education Telecommunication System, KMC Controls, and Carrier Corporation.

\section{REFERENCES}

[1] Hutzel, W. J. (2001). Energy conservation in thermal power courses, Proceedings of the 2001 Annual American Society for Engineering Education Annual Conference.

[2] Hutzel, W. J., \& Webber, P. L. (2003). Evaluating the efficiency of a photovoltaic power system, Engineering the Future: Proceedings of the 2003 ASEE IL/IN Regional Conference, American Society for Engineering Education, pp. 39-40.

[3] Hutzel, W. J. (1999). Digital controls for an active solar collector loop, Proceedings of the 1999 ASME International Mechanical Engineering Congress \& Exposition, Paper No 99-WA/MET-1.

[4] Chumbley, L.S., Hargrave, C.P., et al. (2002). Project ExCEL: Webbased Scanning Electron Microscopy for K-12 Education, Journal of Engineering Education, April 2002.

[5] Feisel, L.D and Peterson, G.D., (2002), A Colloquy on Learning Objectives for Engineering Education Laboratories, Proceedings of the 2002 American Society of Engineering Education Annual Conference. 